\title{
Simulation and Analysis of a Compact Electronic Infrastructure for DC Micro-Grid: Necessity and Challenges
}

\author{
Mohammad Ali Tavakkoli, Ahmad Radan, Houshang Hassibi \\ Department of Electrical Engineering, K. N. Toosi University of Technology, Tehran, Iran. \\ Email: tavakkoli@ee.kntu.ac.ir, \{radan, hassibi\}@eetd.kntu.ac.ir
}

Received February $14^{\text {th }}, 2012$; revised March 20 ${ }^{\text {th }}, 2012$; accepted March $28^{\text {th }}, 2012$

\begin{abstract}
Complex circuitry of electronic infrastructure of compact micro-grids with multiple renewable energy sources feeding the loads using parallel operation of inverters acts as a deterrent in developing such systems. This paper deals with applicable techniques reducing the driving circuits in parallel power inverters used in micro-grid system (MGS), mainly focused on the distributed generation (DG) in islanded mode. The method introduced in this paper, gives a minimal and compressed circuitry that can be implemented very cost-effectively with simple components. DC micro-grids are proposed and researched for the good connection with DC output type sources such as photovoltaic (PV), fuel cell, and secondary battery. In this paper, the electronic infrastructure of micro-grid is expressed. Then discussed the reasons for its complexity and the possibility of reducing the elements of electronic circuits are investigated. The reason for this is in order to compact DC micro-grid system for electrification to places like villages. Digital Simulation in Matlab Simulink is used to show the effectiveness of this novel driver topology for parallel operating inverters (NDTPI).
\end{abstract}

Keywords: Drive Circuitry; Integrated Power Electronics Modules; Micro-Grid

\section{Introduction}

Distributed Generation (DG) is an approach that employs small-scale technologies to produce electricity close to the end users of power. Today's DG technologies often consist of renewable generators (i.e. solar PV, wind turbines, micro turbines), and offer a number of potential benefits. In many cases, distributed generators can provide lower-cost electricity and higher power reliability and security with fewer environmental consequences than traditional bulk power generators [1].

"Smart grid" generally refers to a class of technology people are using to bring utility electricity delivery systems into the 21st century, using computer-based remote control and automation. The "grid" amounts to the networks that carry electricity from the plants where it is generated to consumers. The grid includes wires, substations, transformers, switches and much more. Much in the way that a "smart" phone these days means a phone with a computer in it, smart grid means "computerizing" the electric utility grid [2].

The interest in Distributed Resources (DR), including both Distributed Generation (DG) and energy storage resources, is increasing due to their technical, economical, reliability and environmental merits. Local aggregation of DR systems and electrical loads results in a Micro-grid. The Micro-grid concept has provided a new paradigm for future distribution power systems [3-6].

Micro-Grid is a small-scale grid that is designed to provide power for local communities. A Micro-Grid is an aggregation of multiple distributed generators (DGs) such as renewable energy sources, conventional generators, in association with energy storage units which work together as a power supply network. Typically, a Micro-Grid operates synchronously in parallel with the main grid. However, there are cases in which a MicroGrid operates in islanded mode, or in a disconnected state. Integration of renewable energy into the utility grid can be at either the transmission level or the distribution level, depending on the scale of generation. Large renewable energy generation such as wind farms are directly interconnected to the transmission system. Small scale distributed generation is generally interconnected to the medium or low voltage distribution systems. This small network can be a residential building, commercial building, is a market or even a village. Micro-grids operate mostly interconnected to the higher Voltage Distribution network, but they can also be operated isolated from the main grid, in case of faults in the upstream network. 
The flexibility of micro-grids comprises important benefits, but their efficient implementation poses very challenging problems, as listed next [7]:

- The benefits Micro-grids provide to power system operation and planning need to be quantified and incorporated into an appropriate commercial and regulatory framework, so that a level playing field for all energy technologies can be established. In order to achieve the full benefits from the operation of Micro-grids, it is important that the integration of the distributed resources into the LV grids, and their relation with the Medium Voltage (MV) network upstream, will contribute to optimize the general operation of the system.

- The coordinated control of a large number of distributed sources with probably conflicting requirements and limited communication imposes the adoption of mostly distributed intelligence techniques.
- The design of Micro-source Controllers enhanced with advanced frequency and voltage control capabilities and possessing ride-through capabilities is essential for the stable operation of Micro-grids, especially in islanded mode of operation.

- The design of smart Storage and Load Controllers able to face the stringent requirements posed by the islanded operation and especially during transition from interconnected to islanded mode is also crucial.

\section{DC Micro-Grid or AC Micro-Grid?}

A micro-grid can be built using AC or DC current network [8]. Figure 1 shows the overview of network connectivity to distributed generation sources [9]. Despite the fact that the AC micro-grid system has a benefit to utilize existing AC grid technologies, protections and standards its application involves some problem of low efficiency

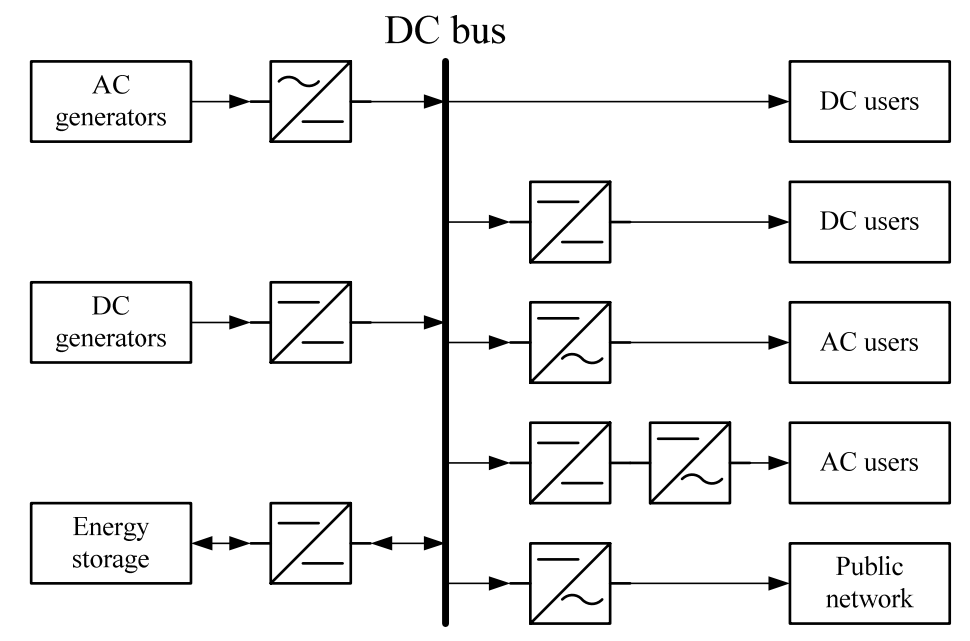

(a)

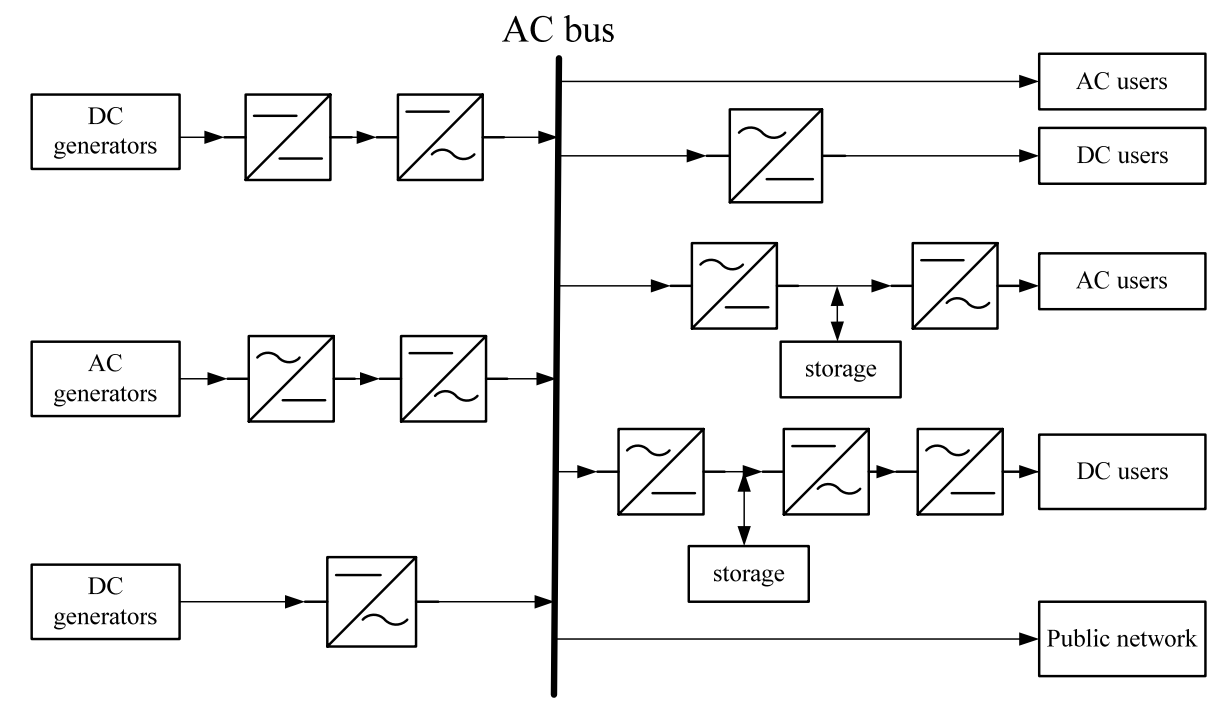

(b)

Figure 1. Types of micro-grid (a) DC micro-grid; (b) AC micro-grid. 
due to the number of power conversions required within the crucial current path from the main grid to the loads. One solution of this problem is the application of a DC micro-grid as an efficient method to combine high reliability and the possibility to reduce the losses. It can eliminate DC/AC or AC/DC power conversion stage and thus has advantages in the stand of efficiency, cost and system size. DC micro-grid is inspired by the absence of reactive power, the possibility of the efficient integration of small-distributed generation units and the fact that, internally, all the loads operate using a DC voltage [10]. AC micro-grid imposed the inverters on both sides, generation and load. Therefore, in recent years has raised the idea of using DC distribution network. DC micro-grid is suitable for home loads which are mainly of DC loads. This method eliminates the ac/dc interface. DC microgrid, also by one or more inverters is connected to the utility grid and industrial loads (ac loads). However, some references [11] have introduced a hybrid network that, the DC link and AC link is used. The DC micro-grid has the following advantages over the AC micro-grid:

- There is no need to consider about synchronization with the utility grid and reactive power [12].

- When a blackout or voltage sag occurs in the utility grid, it does not affect dc bus voltage of dc micro-grid directly due to the stored energy of the dc capacitor and the voltage control of AC/DC converter. Therefore, DGs in DC system are not easy to trip against these disturbances. In other words, DC micro-grid already has fault-ride through capability in its own [12].

- No need for frequency and phase control: Because DC micro-grid, through a DC/AC converter connects to utility grid. Therefore, any change in frequency network does not affect the operating frequency and other ac loads of micro-grid.

- Number of converters used in the DC bus is lower than the AC bus [9]. In [13] has shown that the connecting energy system combining fuel cell and solar cell using DC bus, inject THD less into the network.

- In DC micro-grid because, AC loads connected to the DC bus this opportunity exists in a condition that is generation power more than load, especially in islanded mode, some non-critical loads out of orbit and was feeding sensitive loads [14].

- In [15] losses comparison between AC micro-grid and DC micro-grid. Shown that losses in DC micro-grid, 15\% lower than the AC Micro-grid.

- In the same conditions, power transmission in DC system is higher than the AC system [16].

- In DC micro-grid, DC cables can be used to reduce the investment cost [16].

- In DC micro-grid voltage only affected by the active power therefore, it is simple to control [17].

- Lack of electrical hazards, other advantages of using a DC bus [18].

Of course, there are some drawbacks to put dc microgrid to practical use as follows [19]:

- It is needed to construct private dc distribution lines for dc micro-grid.

- The protection in dc system is more difficult than the AC system's because there is no zero cross point of voltage in DC system.

- The loads adapted for dc power supply are required for high system efficiency.

\section{Prerequisite Micro-Grid}

The smart-grid will incorporate a variety of technologies and tools, allowing the grid to work far more efficiently. The US Department of Energy has listed five fundamental technologies that will drive the smart grid; these technologies include [1]:

- Integrated communications, connecting components to open architecture for real-time information and control, allowing every part of the grid to both "talk" and "listen".

- Sensing and measurement technologies, to support faster and more accurate response, such as remote monitoring.

- Advanced components, to apply the latest research in superconductivity, storage, power electronics and diagnostics.

- Advanced control methods, to monitor essential components, enabling rapid diagnosis and precise solutions appropriate to any event.

- Improved interfaces and decision support, to amplify human decision-making, transforming grid operators and managers into visionaries when it comes to seeing into their systems.

Because this paper focuses on power electronics devices and electronic infrastructure, therefore, the more details about the third technology that is related to this subject are presented.

Different distributed energy systems require various power electronics topologies for converting the generated power to the utility compatible power. The photovoltaic (PV) and fuel cell systems generate DC power which needs to be converted to single-or three-phase AC for utility connection. Additionally, an isolated DC-DC converter is often used before the DC-AC inverter in order to avoid bulky line frequency transformers for isolation and voltage boosts. Wind micro turbine systems generate variable frequency AC output which must be converted into $50 \mathrm{~Hz}$ AC for utility connection. The use of a back-toback converter is the most efficient way to utilize the generated power. Typically, most internal combustion (IC) engines are interconnected to the utility through a fixedspeed synchronous generator that has protective relays. A 
back-to-back voltage source converter is the most suitable choice for IC engine applications. Inclusion of storage in the distributed energy system actually provides the user with dispatch capability of its distributed resources, which are generally renewable energy sources like PV and wind, having no dispatch ability on their own. The stored energy can then be used to provide electricity during periods of high demand. Depending on the type of storage, PE converters are required for utility connection. The most unique aspect to power electronics for energy storage is that they must be bidirectional, both taking power from the grid during charging and providing power for the grid during discharge. For the battery energy storage system (BESS), a bidirectional DC-DC converter followed by a DC-AC inverter is the most general choice, whereas the flywheel system can utilize a back-to-back converter for utility connection.

\section{Electronic Infrastructure of DC Micro-Grid}

The power electronic systems play an important role in DC Micro-grid that to use them; appropriate electronic infrastructure should be designed. For example, isolation circuit, drive circuit, sensors, etc. collection of electronic circuits as the infrastructure, these networks will be complex. For electrification to villages, and also where there is not enough land to install the system, the compact system will be very important. Using the system properties and circuits that have similar functions, electronic infrastructure can be compressed. IGBT driver circuit and isolation circuit are capable of compression.

\subsection{IGBT Driver Circuit}

\subsubsection{Parallel Inverter}

To reduce the number of driver circuits, first the different methods of driver are reviewed.

\subsubsection{Driver Circuit with Isolation Transformer}

Circuit of this method is shown in Figure 2, where the signal after passing through a transformer is connected to the IGBT gate. To turn the two switches with a command, two modes are consider: the first case, the source of the two circuits with different voltage that in this case the gate-source voltages of the two switches must be isolated. Therefore, must use a transformer with two separate secondary windings Figure 3. In the second case is assumed that the source potential of the two switches is the same. This situation occurs for upper switch in the parallel inverter. As can be seen in Figure 4, a driver circuit to supply both the switches is used.

So we conclude that, when a load at DC micro-grid is fed by two parallel inverters; if the above method is used the transformer for high-side switches will be reduced

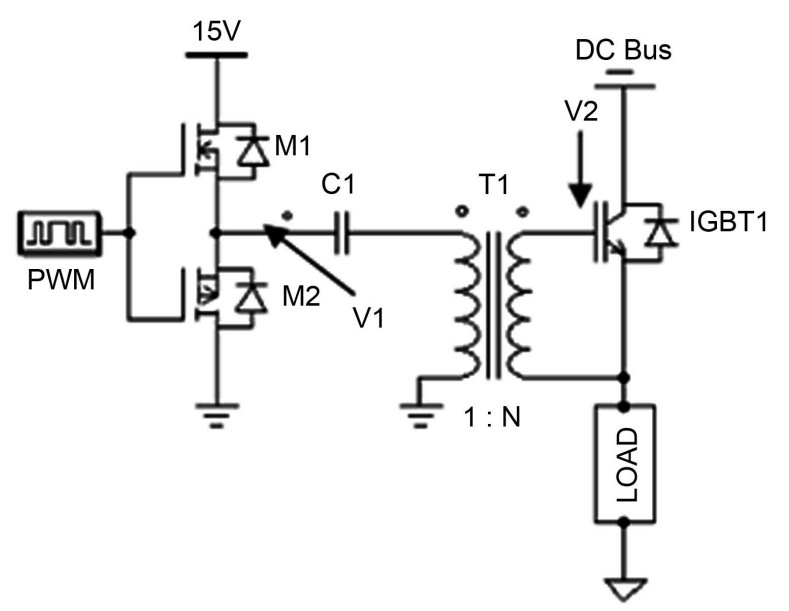

Figure 2. Combined transformer level shifter and gate driver [20].

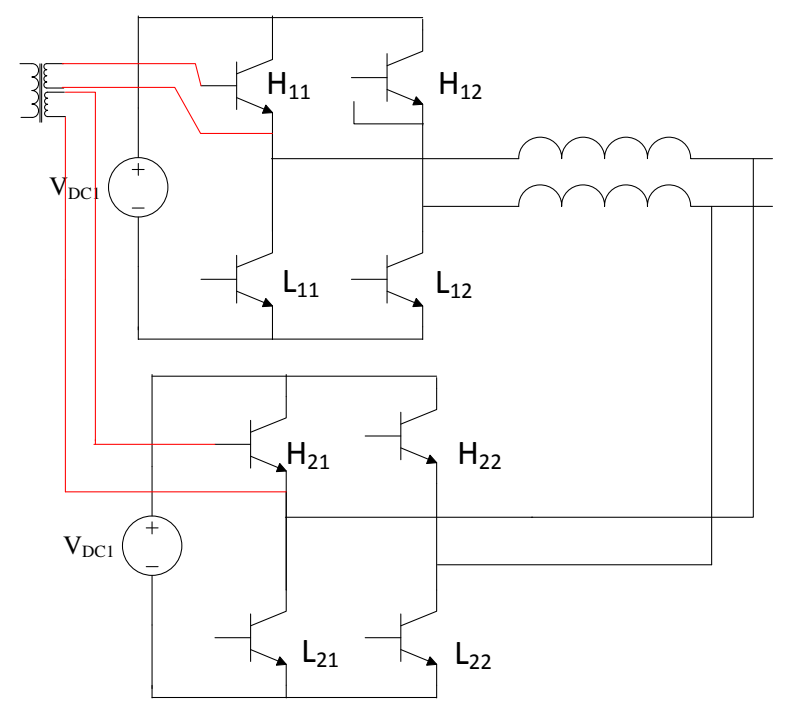

Figure 3. Drive circuit of two separate switches of two parallel inverters.

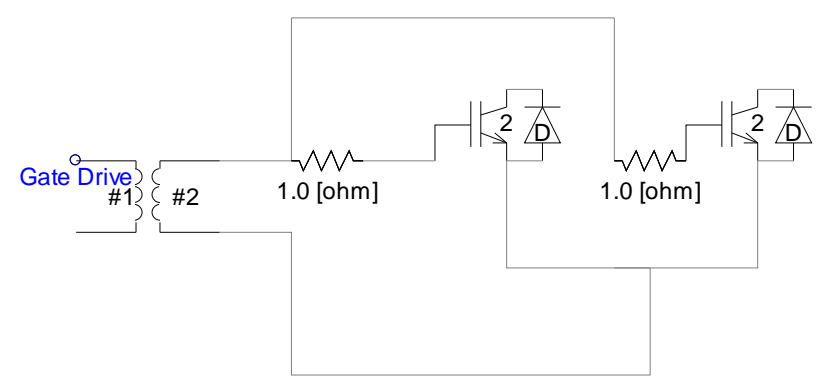

Figure 4. Drive circuit of two switches in parallel inverters with same source.

three. It should be noted that generally the use of transformers, the system will be large. But if there is an insistence that the isolation transformer is used to drive switches; method described reduces the cost and the electronic infrastructure will be smaller. 


\subsubsection{Bootstrap Technique}

In voltage inverter switches, the two switches, in a leg, cannot be turn on at the same time, on the contrary one is on and the other one is off, and vise versa. The bootstrap connection provides the advantage of using two similar switching circuitry for high and low sides; on the other hand a very low supply voltage is needed to drive these two switches at the same time Figure 5.

When the low-side switch $M_{2}$ is on, the bootstrap diode, D, conducts and charges the storage capacitor. If we assume the saturation voltage drop of the low-side power device $M_{2}$ and the forward volt drop of diode $D$ to be negligible, the capacitor will charge to approximately the low voltage supply potential. When the high-side switch $M_{1}$ is on low side switch $M_{2}$ is off, $D$ is reverse-biased and the high-side circuitry is powered from C. In this condition, the voltage on $\mathrm{C}$ droops as it discharges when supplying the high-side circuitry [20].

Novel driver topology for parallel operating inverters (NDTPI) proposed and described in detail in the previous papers of the authors [21]. In Figure 6, two inverters are parallel that driver circuit is optimized. The implemented switches in this figure have two different types: the lowside uses IC-drive and high-side uses the bootstrap technique. In this case either of inverter have a common

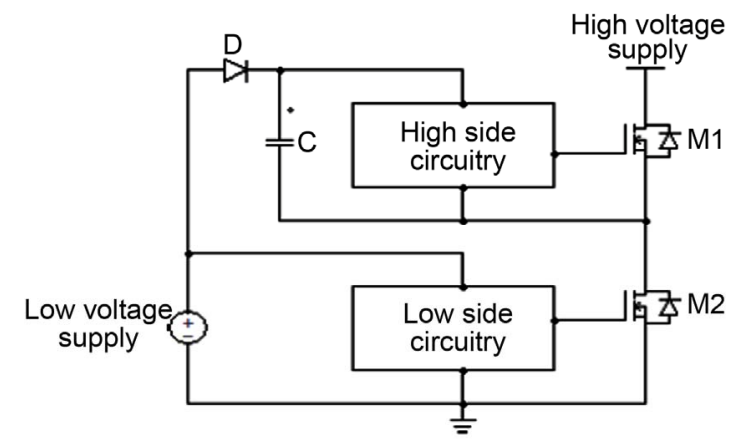

Figure 5. Bootstrap technique employed for creating a floating supply [20].

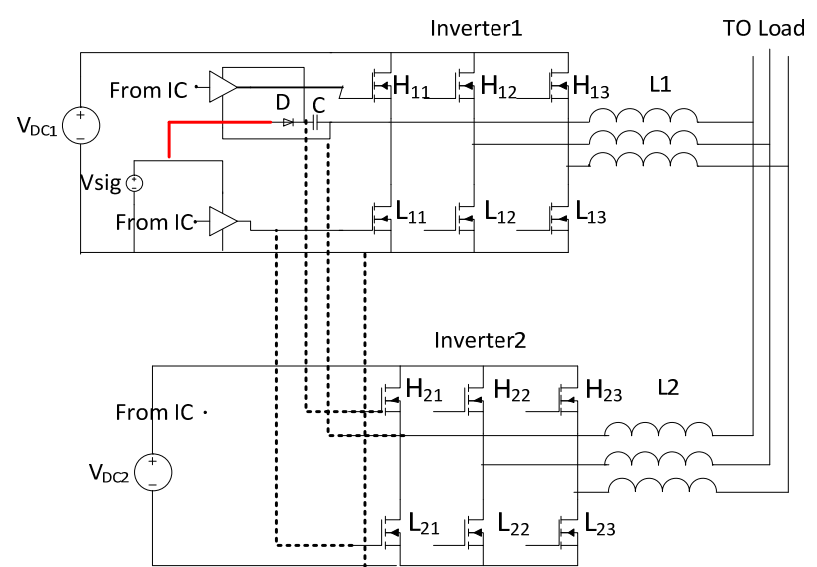

Figure 6. Parallel inverters with common ground [21]. ground and inverters commands are same. If each switch, a driver is used; then the number of the drive circuit will be twelve. However, this method has been used only three drivers. Thus, the parallel capabilities of the inverters in Micro Grid can be used to reduce the number of drive to a quarter; of course for two parallel inverters. This method can develop for more than two parallel inverters [21].

As discussed above, the bootstrap technique has the capability which can be use this feature and brief drive circuit. In addition to reducing costs and also reduce the size of the electronic infrastructure.

\subsubsection{Optocoupler}

Using an optocoupler, can be fed the switch that its source is float. The main structure of the optocoupler circuit is shown in Figure 7. Optocoupler is requires a separate supply both the input and output that necessary to use a DC/DC isolated with driver circuit. Despite difficulties, due to the very good compatibility with the IC, this device now is the best way to drive floating switches.

In parallel inverter that use optocoupler, for drive highside switches is needed use of a separate optocoupler. But according to Figure 8, for the lower switch can be used from an optocoupler.

So we conclude, as the isolation transformer in parallel inverter number three optocoupler reduced. But the main problem with this method, the IC is too costly.

\subsubsection{Centralized Driver Circuit of Three-Phase Inverter}

In DC micro-grid, for supply three-phase loads, threephase inverter is used. In this section, centralized driver

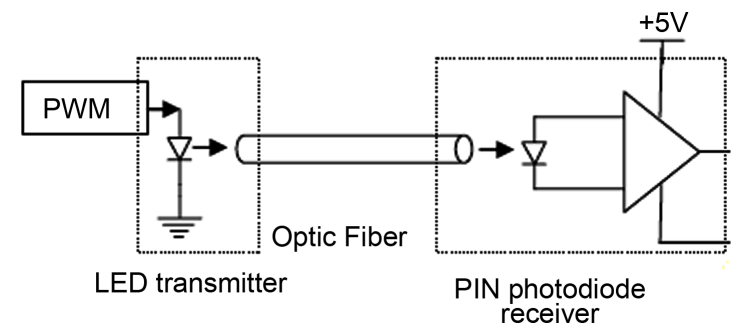

Figure 7. Main structure of optocoupler [20].

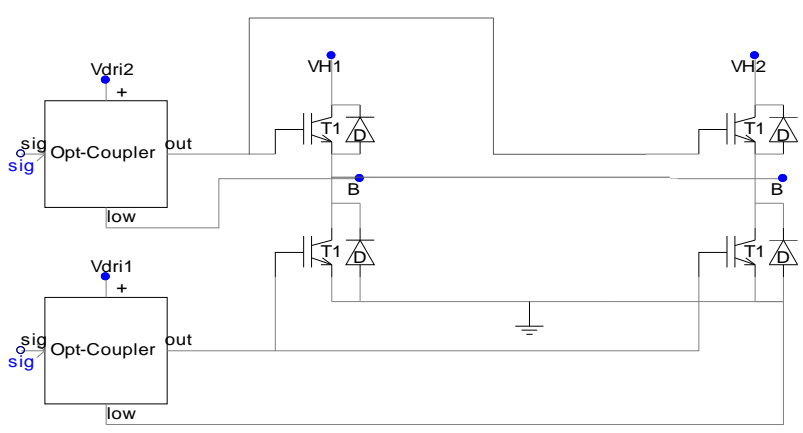

Figure 8. Driver circuit optocoupler in parallel inverter. 
circuit is introduced. In this type of inverter for high-side switch, in each leg, used one bootstrap circuit. If highside switches, in three legs, turned on together, then remove any bootstrap drive circuit is not possible. But it should be noted that, switch on together three high-side switches means of the output voltage is zero. That, equivalent to three low-side switches can be turned on. Figure 9, shows the method for avoid to turn on the highside switches at the same time. The commands of the driver circuit with the proposed switching method illustrated in Figure 10. The switching process of the proposed method is shown in Figure 11.

\subsection{Isolation Circuit}

In DC micro-grid each sources of energy such as solar, fuel cell and battery reserve through a converter $\mathrm{dc} / \mathrm{dc}$ Buck Boost can be connected to the network. In Figure 12, Buck Boost topology is shown. As can be observed due to the floating source voltage, to drive any of the switches an isolation circuit is needed.

Considering the significant number of dc/dc converter in solar energy sources as MPPT, removing driver circuit isolation can be reduced circuit size and cost. Cuk converter can be used to solve this problem that its topology is shown in Figure 13, in this topology, source of switch connected to the ground. After using cuk converters, isolation circuit can be eliminated.

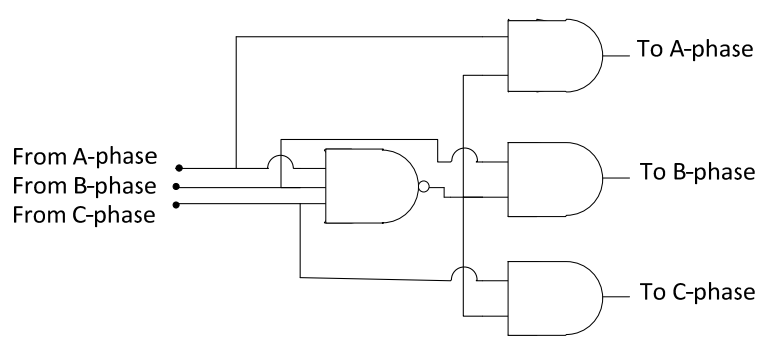

Figure 9. Method for avoid to turn on the high-side switches at the same time.

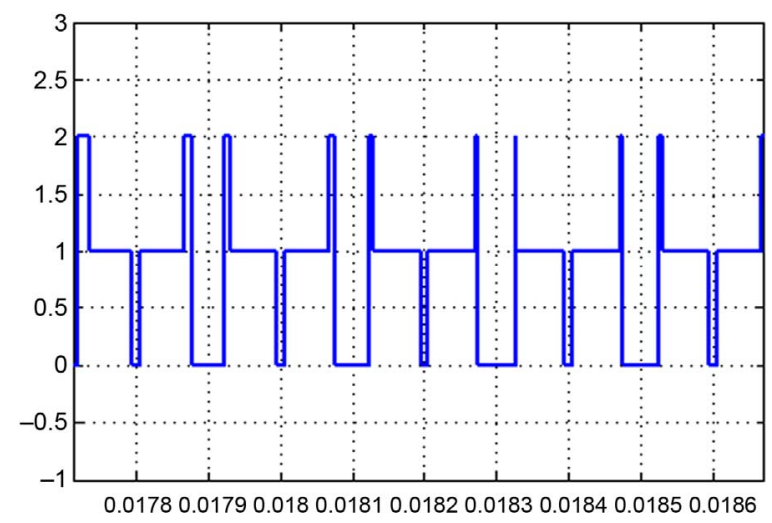

Figure 10. The commands of the driver circuit with the proposed switching method.

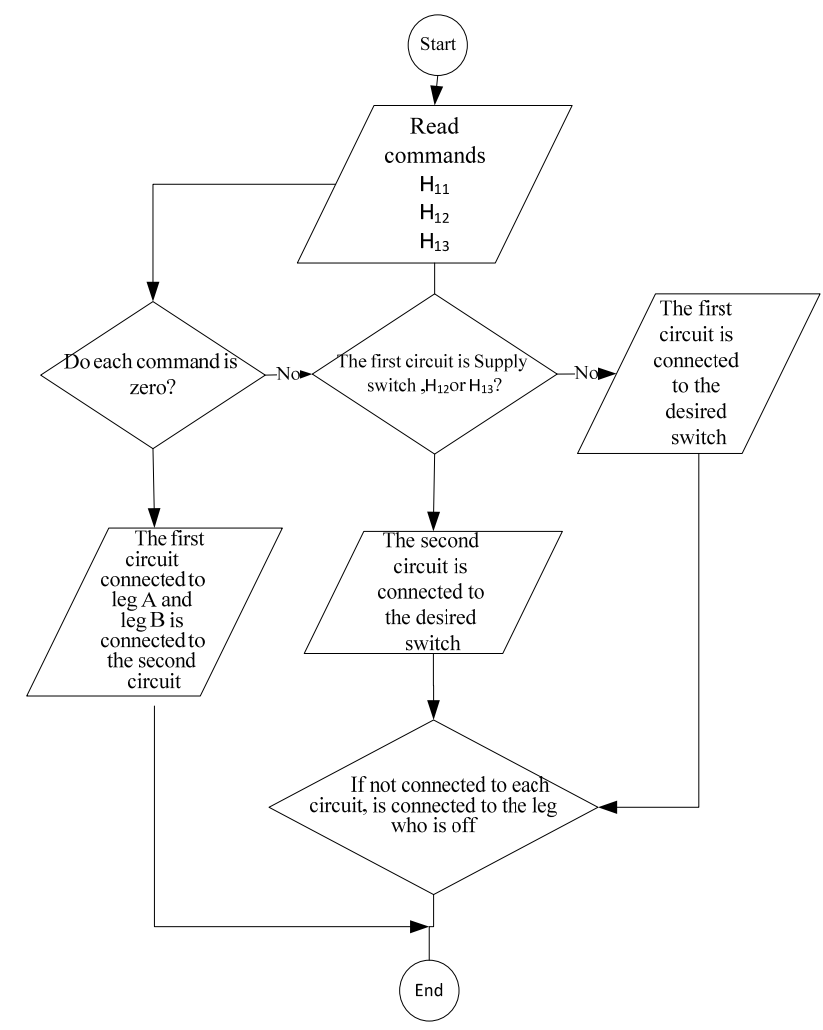

Figure 11. The proposed algorithm for controlling the driver circuit.

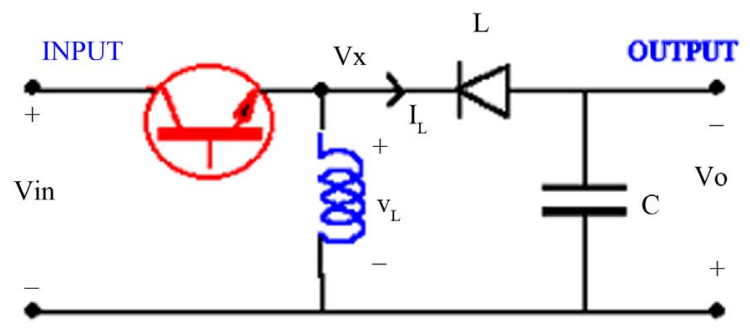

Figure 12. Buck boost topology.

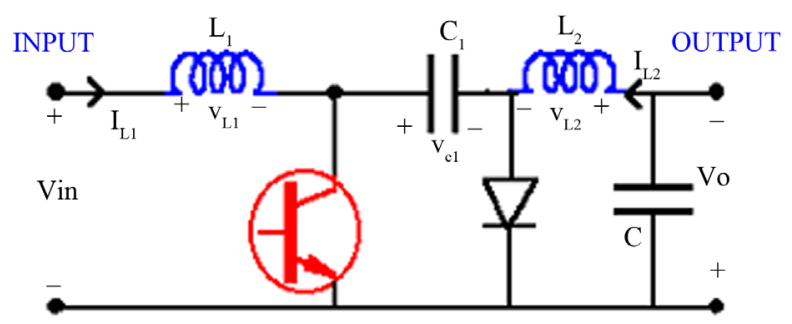

Figure 13. Cuk topology.

\section{Simulation Results}

\subsection{Drive Circuit of Parallel Inverter}

To analyze the presented structure correctness, two parallel inverters connected to a common load at Simulink MATLAB is simulated whose results are given in next section. In this case both inverters have common ground. 
In part of the drive circuit, because the emphasis is on bootstrap technique then simulation results this technique will be shown that described in detail in the previous papers of the authors [21].

The power circuit for the complete inverters system is shown in Figure 6. The DC input stage of the inverters consists of a 500V DC source along with two inductors have been serried with each switch, before they are connected to the load, for damp out the transient current.

Figure 14, presents gate source voltage of switch $\mathrm{H}_{11}$ while drive by an IC-driver separated without bootstrap method, Figures 15-19, presents conditions at which inverters are common in ground, Figure 15, shows lowside switches gate source voltage $\left(\mathrm{L}_{21}\right)$ and Figure 16, shows high-side switch gate source voltage $\left(\mathrm{H}_{11}\right)$ that maximum voltage is 14 volt, the voltage drop is due to bootstrap capacitor discharge at the time of $\left(\mathrm{H}_{\mathrm{X}}\right)$ switches run up.

Figure 17 shows gate source voltage $\left(\mathrm{H}_{21}\right)$ and Figure 18 shows bootstrap capacitor voltage to the ground whose voltage is about 500 volt. Figure 19 is presented to confirm inverters performance with suggested structure.

For simplicity, in Figure 6 the driver circuit for a phase is shown; but similarly to the other phases of the sample used.

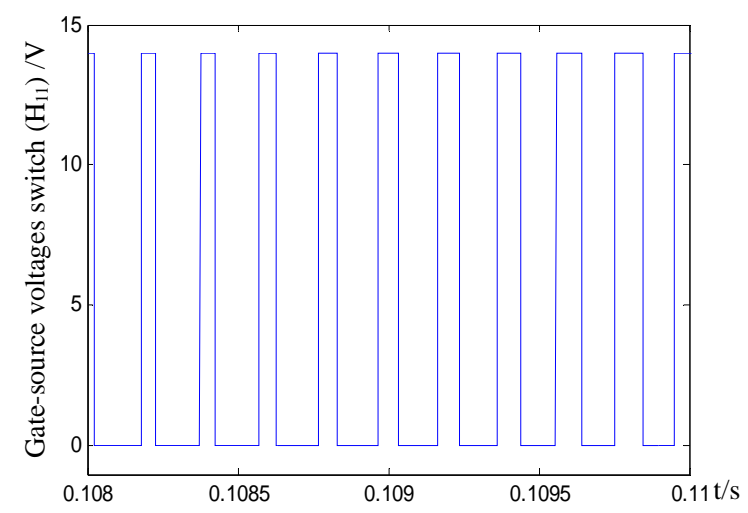

Figure 14. $\mathrm{H}_{11}$ switch gate source voltage.

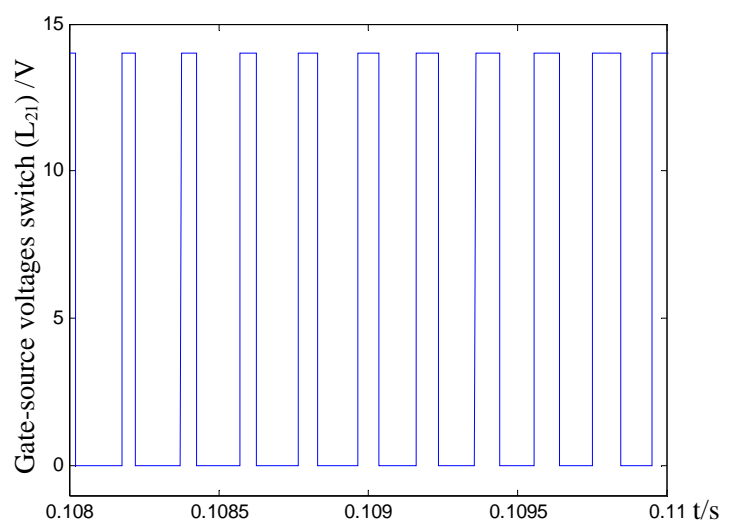

Figure 15. $L_{21}$ switch gate source voltage.

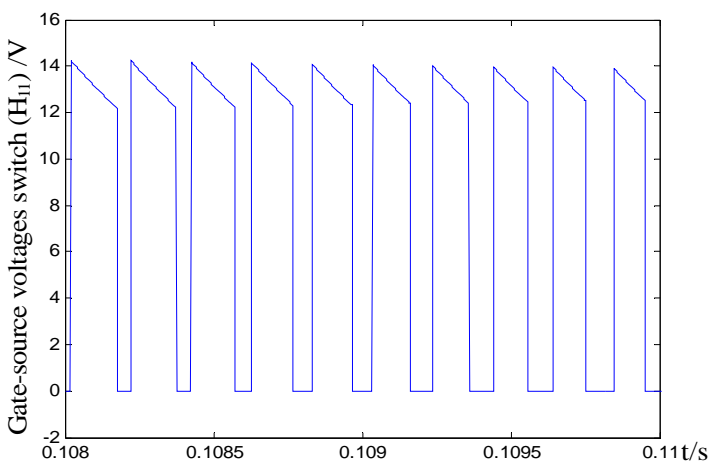

Figure 16. $H_{11}$ switch gate source voltage.

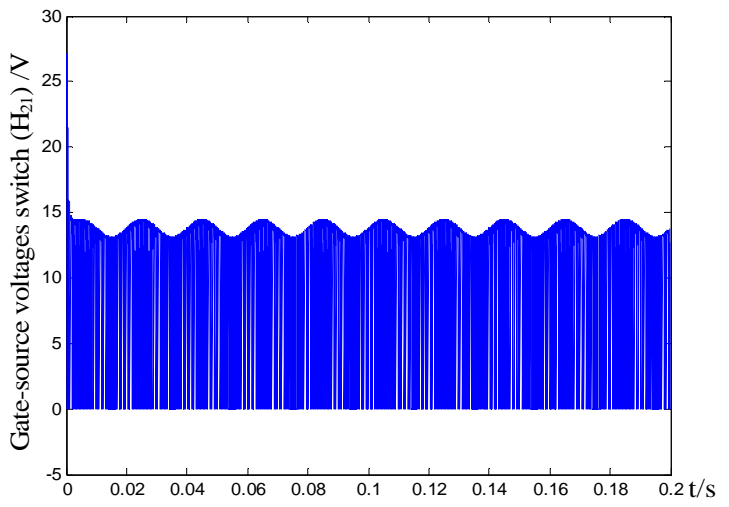

Figure 17. $H_{21}$ gate source voltage in common ground condition.

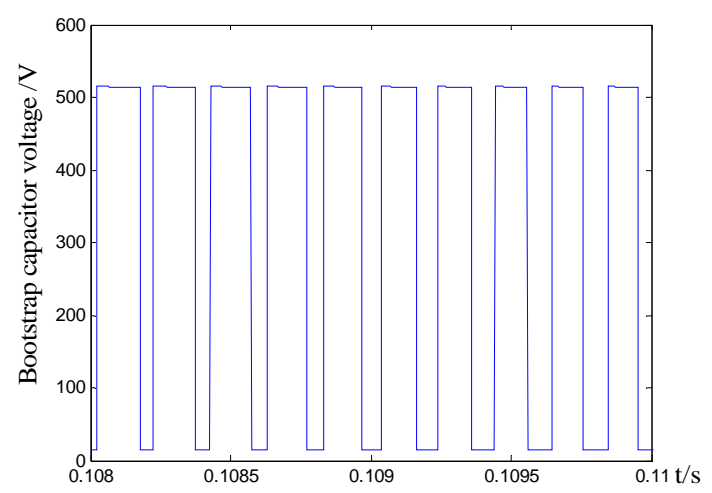

Figure 18. Bootstrap capacitor voltage to the ground.

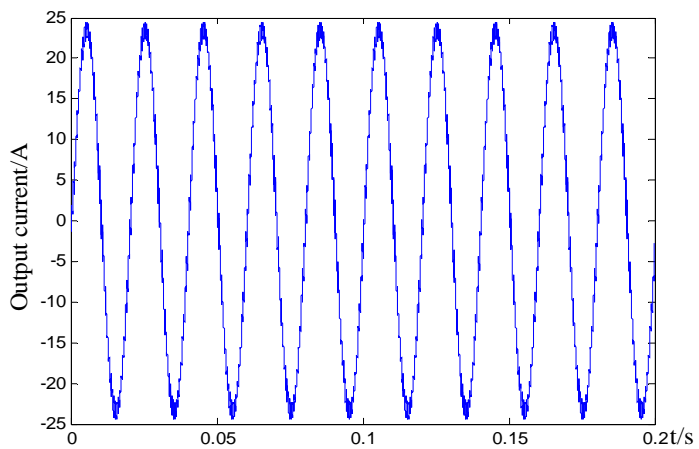

Figure 19. Parallel inverter output current. 


\subsection{Isolation Circuit}

In Figure 20 each source such as solar, fuel cell and battery reserve through a converter dc/dc Buck Boost or cuk connected to DC bus that its voltage value constant $48 \mathrm{~V}$. Simulation results are shown in Figures 21 and 22.

\subsection{Drive Circuit of Three-Phase Inverter}

In Figures 23 and 24, inverter output voltage and frequency spectrum it shows. Voltage three-phase inverter with the conventional bootstrap circuit is quite similar. Figures 25 and 26 show the gate-source voltage switch $\mathrm{H}_{11}$. Figure 25 shows the envelope curve in any one of points; the applied voltage to the switch $\mathrm{H}_{11}$ limit is not exceeded. The peak voltage in Figure 26, a bootstrap capacitor discharge is visible.

For the circuit is functioning correctly the bootstrap capacitors are able to supply enough energy to turn the switch. Figures $\mathbf{2 7}$ and $\mathbf{2 8}$ in the voltage across this capacitor are shown. Be seen, voltage across bootstrap capacitor at about 15 volts and the capacitor voltage ripple is $13 \%$ that is acceptable. Therefore, two circuits are well able to supply enough energy to turn switches.

\section{Conclusion}

Electrification to home load, market, commercial building or even villages and also where there is not enough land to install the system, the compact system will be very important. One of the ideas in this regard is the use of the

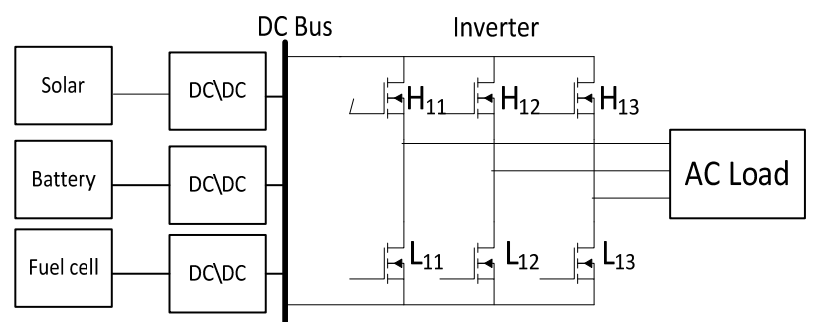

Figure 20. DC micro-grid.

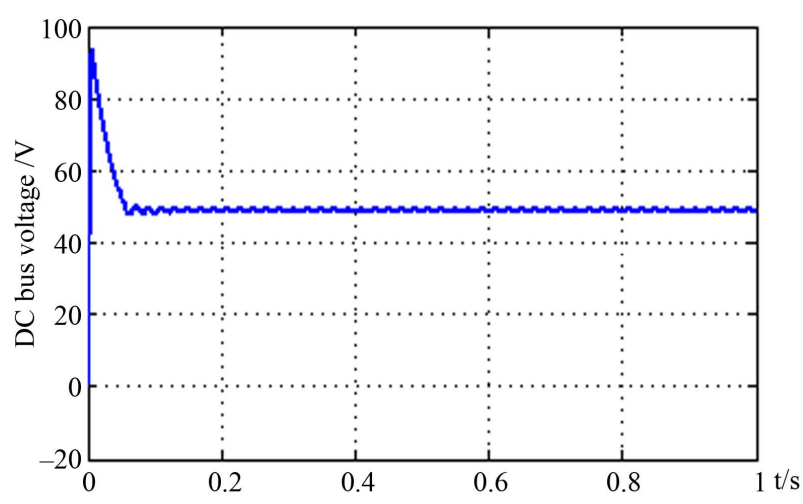

Figure 21. DC bus voltage with Buck boost converter.

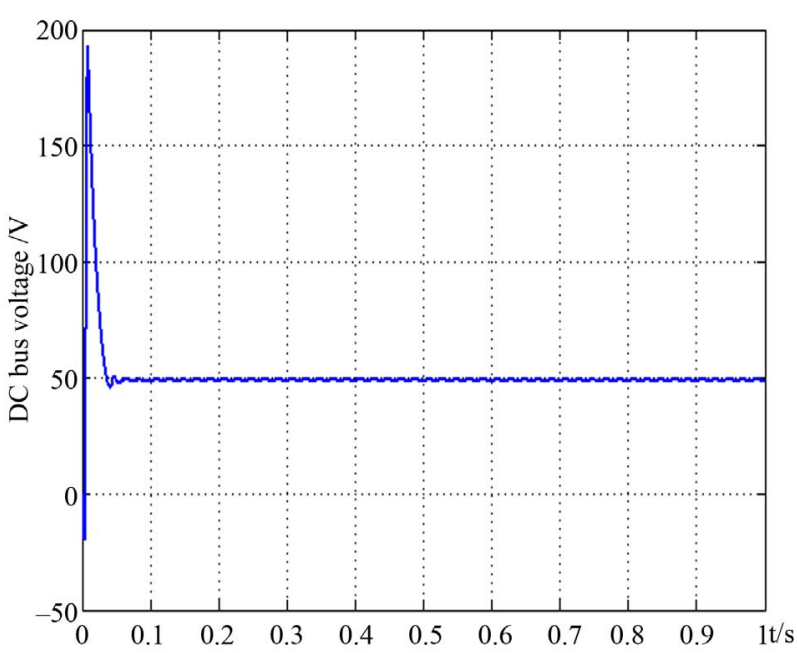

Figure 22. DC bus voltage with cuk converter.

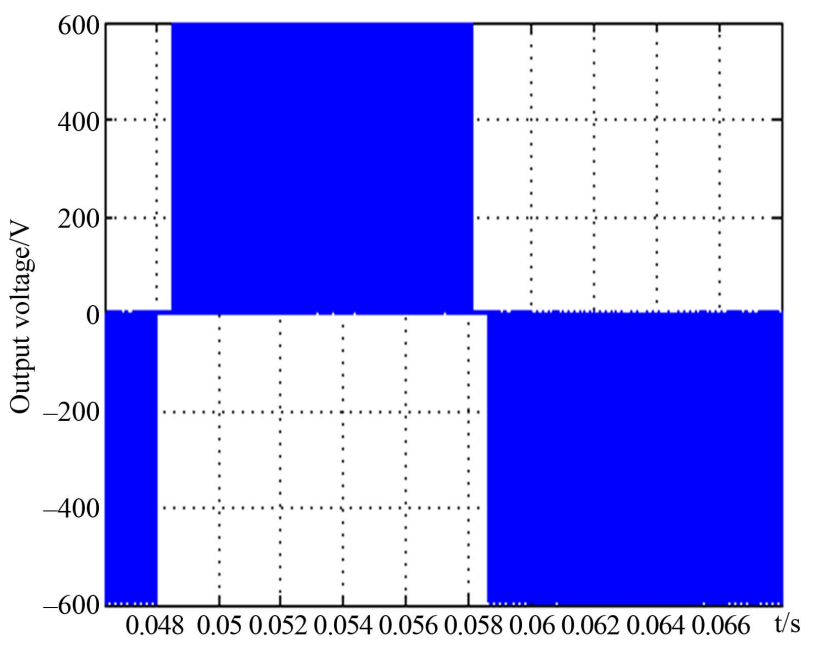

Figure 23. Output voltage of three-phase inverter with the proposed switching method.

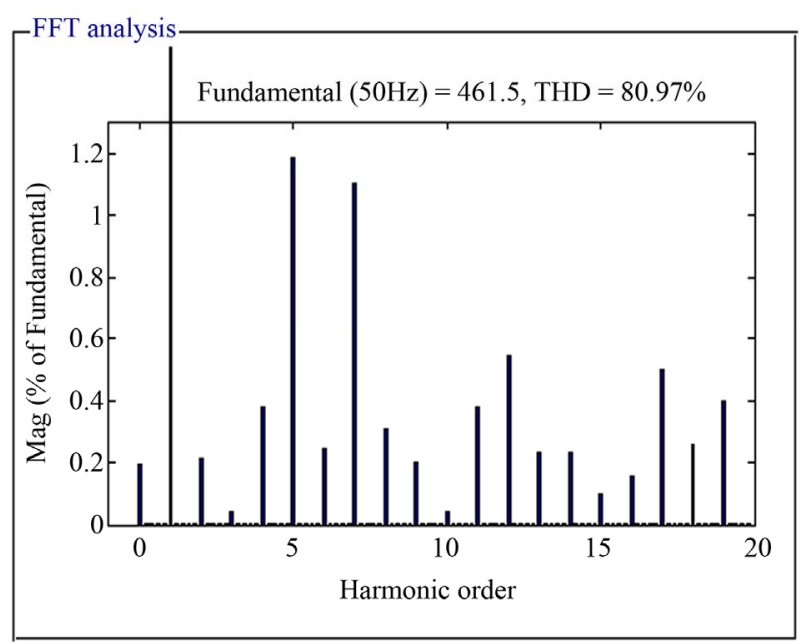

Figure 24. Frequency spectrum with the proposed switching method. 


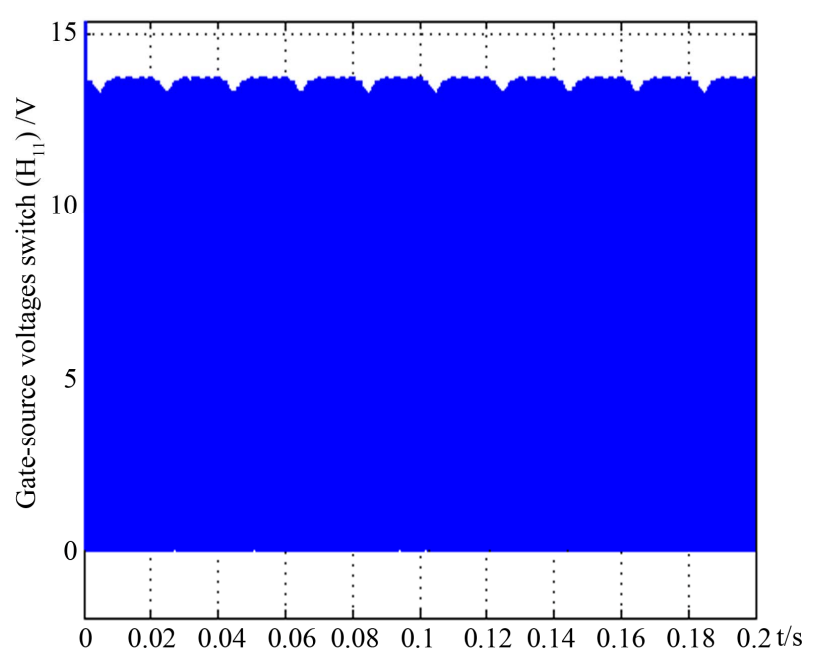

Figure 25. Push the $\mathbf{H}_{11}$ switch gate-source voltage.

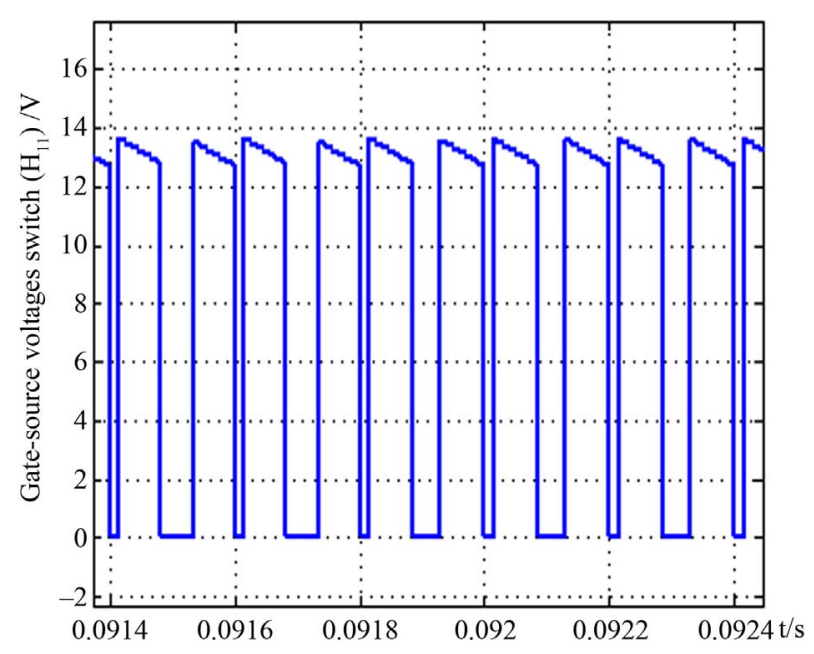

Figure 26. $\mathrm{H}_{11}$ switch gate-source voltage.

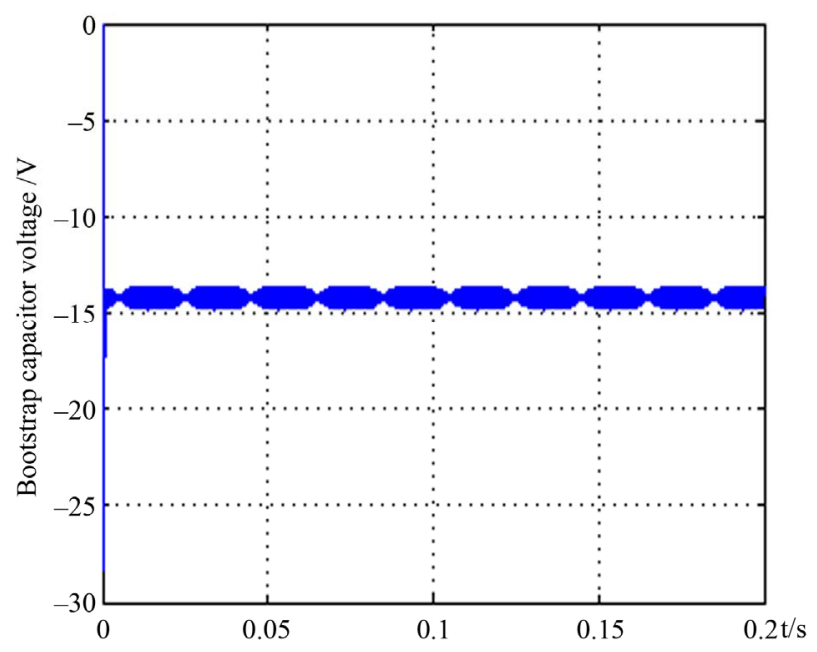

Figure 27. Bootstrap capacitor voltage in first bootstrap circuit.

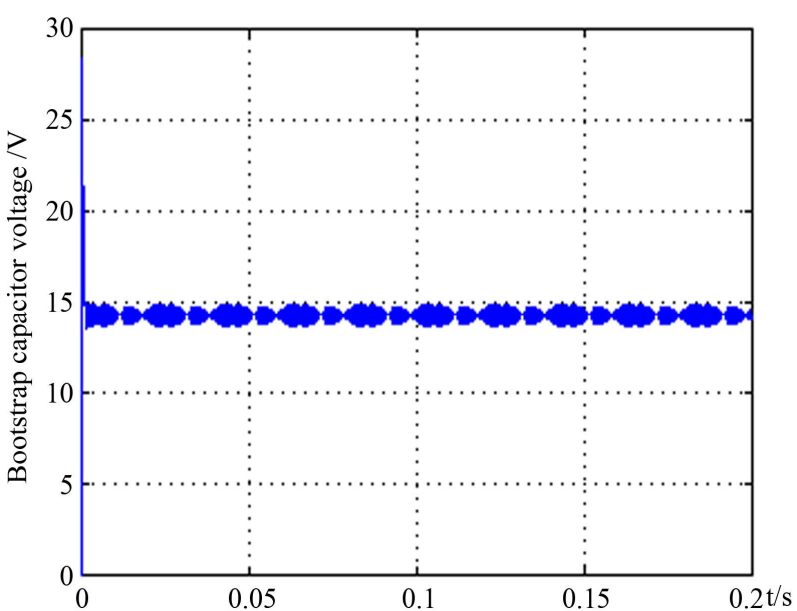

Figure 28. Bootstrap capacitor voltage in second bootstrap circuit.

DC micro-grid. It can eliminate DC/AC or AC/DC power conversion stage and thus has advantages in the stand of efficiency, cost and system size. But the idea has been proposed in this paper that the DC system will be smaller. Using the system properties and circuits that have similar functions, electronic infrastructure can be compressed. IGBT driver circuit and isolation circuit are capable of compression. In this paper, an electronic infrastructure for driving and isolation with less circuitry of parallel operating inverter and three-phase inverter were presented.

\section{REFERENCES}

[1] K. Doran, F. Barnes and P. Pasrich, "Smart Grid Deployment in Colorado Challenges and Opportunities,” 2010. http://www.cees.colorado.edu

[2] http://www.sgiclearinghouse.org

[3] M. Stadler, H. Aki, R. Firestone, J. Lai, C. Marnay and A. Siddiqui, "Distributed Energy Resources On-Site Optimization for Commercial Buildings with Electric and Thermal Storage Technologies,” Environmental Energy Technologies Division, Berkeley, 2008.

[4] C. Marnay, M. Stadler, H. Aki, B. Coffey, R. Firestone, J. Lai and A. Siddiqui, "Microgrid Selection and Operation for Commercial Buildings in California and New York States," 4th European PV-Hybrid and Mini-Grid Conference, Glyfada, 29-30 May 2008,.

[5] C. Marnay, "Microgrids: An Emerging Paradigm for Meeting Building Electricity and Heat Requirements Efficiently and with Appropriate Energy Quality,” European Council for an Energy Efficient Economy Summer Study, La Colle sur Loup, 1-6 June 2007.

[6] C. Marnay, "Microgrids and Heterogeneous Security, Quality, Reliability and Availability,” Power Conversion Conference, Nagoya, 2-5 April 2007. doi:10.1109/PCCON.2007.373031

[7] "Advanced Architectures and Control Concepts for More Microgrids,” January 2006-December 2009. 
http://www.power.ece.ntua.gr

[8] Y. W. Li and L. M. Tolbert, "Control and Protection of Power Electronics Interfaced Distributed Generation Systems in a Customer-Driven Microgrid” Power \& Energy Society General Meeting, Calgary, 26-30 July 2009, pp. 1-8.

[9] E. Borioli, M. Brenna, R. Faranda and G. Simioli, “A Comparison between the Electrical Capabilities of the Cables Used in LV AC and DC Power Lines," 11th International Conference on Harmonics and Quality of Power, New York, 12-15 September 2004, pp. 408-413.

[10] A. Palamar and M. Karpinskyy, "Control of an Uninterruptible Power Supply in a DC Microgrid System,” 10th International Symposium Opical Problems in the Field of Electrical and Power Engineering, Pärnu, 10-15 January 2011, pp. 80-84.

[11] Z. H. Jiang and X. W. Yu, "Hybrid DC- and AC-Linked Microgrids: Towards Integration of Distributed Energy Resources," Energy 2030 Conference, Atlanta, 17-18 November 2008, pp. 1-8.

[12] H. Kakigano, M. Nomura and T. Ise, "Loss Evaluation of DC Distribution for Residential Houses Compared with AC System,” The International Power Electronics Conference, San Luis Potosi, 21-24 June 2010, pp. 480-486.

[13] D. Sabaripandiyan and S. Arul Daniel, "A Comparative Review on Small Scale Integration of Hybrid Fuel Cell and PV Generating System to Utility Network," International Conference on Industrial and Information Systems, Mangalore, 29 July-1 August 2010, pp. 590-595. doi:10.1109/ICIINFS.2010.5578638

[14] H. Kakigano, Y. Miura, T. Ise and R. Uchida, "DC Voltage Control of the DC Micro-Grid for Super High Quality Distribution,” Power Conversion Conference, Nagoya, 2-
5 April 2007, pp. 518-525. doi:10.1109/PCCON.2007.373016

[15] H. Kakigano, M. Nomura and T. Ise, "Loss Evaluation of DC Distribution for Residential Houses Compared with AC System,” International Power Electronics Conference, Sapporo, 21-24 June 2010, pp. 480-486. doi:10.1109/IPEC.2010.5543501

[16] H. Kakigano, Y. Miura, T. Ise, T. Momose and H. Hayakawa, "Fundamental Characteristics of DC microgrid for Residential Houses with Cogeneration System in Each House," IEEE Power and Energy Society General Meeting-Conversion and Delivery of Electrical Energy in the 21st Century, Pittsburgh, 20-24 July 2008, pp. 1-8.

[17] D. Thukaram, L. Jenkins and K. Visakha, “Optimum Allocation of Reactive Power for voltage Stability Improvement in AC-DC Power Systems,” IEE Proceedings Generation, Transmission and Distribution, Vol. 153, No. 2, 2006, pp. 237-246. doi:10.1049/ip-gtd:20045210

[18] K. Fitzgerald, I. Nair and M. Granger, "Electromagnetic Fields: The Jury's Still Out,” IEEE Spectrum, Vol. 27, No. 8, 1990, pp. 23-35.

[19] H. Kakigano, Y. Miura and T. Ise, "Low Voltage Bipolar Type DC Microgrid for Super High Quality Distribution,” IEEE Transactions on Power Electronics, Vol. 25, No. 12, 2010, pp. 3066-3075. doi:10.1109/TPEL.2010.2077682

[20] M. H. Rashid, “Power Electronics Handbook,"2nd Edition, Academic Press, Cambridge, 2006, pp. 543-558.

[21] M. A. Tavakkoli, A. Radan and H. Hassibi, "Investigation of Electronic Infrastructure of a Compact Micro Grid with DC Common Bus for Utilizing Multiple Renewable Energy Sources," The Second Iranian Conference on Renewable Energy and Distributed Generation, Tehran, 6-8 March 2012, pp. 110-115. 